\title{
Evaluate five different diagnostic tests for dry mouth assessment in geriatric residents in long-term institutions in Taiwan
}

\author{
Yao-Ming Cheng ${ }^{1}$, Shao-Huan Lan², Yen-Ping Hsieh ${ }^{3^{*}} \mathbb{D}$, Shou-Jen Lan ${ }^{1,4}$ and Shang-Wei Hsu'
}

\begin{abstract}
Background: Residents in long-term care (LTC) institutions require care plans to effectively resolve dry mouth. Simple and easily comprehensible dry mouth indices must be developed to assist care professionals in determining dry mouth among residents. Therefore, this study aim of the study was to evaluate five different diagnostic tests for dry mouth assessment.
\end{abstract}

Methods: A total of 568 residents were recruited from several LTC institutions in central Taiwan. The research instruments and tools comprised of the characteristics of the residents, state of oral health care, self-perceived ability to chew food, Taiwanese short-form of the Oral Health Impact Profile (OHIP-7 T), self-perceived levels of dry mouth, oral moisture checking, and a repetitive saliva swallowing test (RSST). The data collected were analyzed through demographic analysis, Correlation coefficient and chi-squared automatic interaction detection.

Results: Results of the decision tree analysis indicated that RSST results, tooth brushing frequency, and age were the three indices that exerted the greatest influence on oral moisture levels. Specifically, in residents with relatively high RSST results, a daily tooth brushing frequency $>1$, and an age $<68$ years exhibited more favorable oral moisture levels. The results indicated that residents' self-perceived oral status was not associated with their oral moisture levels.

Conclusion: The three indices can be provided to LTC institutions for on-site assessment of dry mouth among residents to facilitate early detection of those with dry mouth.

Keywords: Dry mouth, Long-term care institution n, Oral moisture, Decision tree

\section{Background}

Residents of long-term care (LTC) institutions usually have poor oral health [1], with dry mouth being one of the primary oral diseases. In addition to the effect of diseases, 20 to $86 \%$ of cases of dry mouth co-occur with salivary hypofunction status [2-4]. The symptomatic dry mouth that can have multivariate negative effects, including chewing difficulty, dysphagia, loss of appetite, malnutrition, oral discomfort, risk of tooth decay, burning-mouth sensation, halitosis, less social interaction, and lowered quality of life [5-11]. Numerous factors influence the occurrence of dry mouth in institutional elderly, and Japanese studies have reported factors such as body mass

\footnotetext{
* Correspondence: yenping2010@gmail.com

${ }^{3}$ Department of Long-term Care, National Quemoy University, No. 1

University Rd., Jinning Township, Kinmen County 89250, Taiwan

Full list of author information is available at the end of the article
}

index (BMI), physical disability, age, mouth breathing, frequency of daily brushing, sex, medication, tube feeding, and level of conversation [12-14].

In addition, an Australian study proposed mechanisms for the management of dry mouth among LTC residents [15], and a Brazilian study reported that residents with dysphagia had dry mouth symptoms greater in number [16].

Studies have suggested that older adults who received nonpharmacological interventions, such as participation in an oral function training program (e.g., massage on salivary gland and face, and tongue muscle training), showed improvement in dry mouth and overall oral status $[2,17,18]$. This demonstrated that older adults' regular participation in oral function training programs is a crucial preventative measure that ensures good oral health. However, improving the ability of caregivers in long-term care institutions to evaluate dry mouth

(c) The Author(s). 2019 Open Access This article is distributed under the terms of the Creative Commons Attribution 4.0 International License (http://creativecommons.org/licenses/by/4.0/), which permits unrestricted use, distribution, and 
symptoms in residents is a prerequisite for such programs. If caregivers can evaluate dry mouth symptoms in institution residents, implementing comprehensive oral health care strategies is possible (including oral medical care and treatment, daily oral cleaning, and oral functional training).

However, implementing oral care in LTC institutions in Taiwan is a challenge. First, oral treatment by dentists is mainly based in hospitals or private clinics, and conducting oral care in LTC institutions is still in the stage of policy encouragement. This is mainly because of the lack of vehicles for transporting residents, inadequate space or medical equipment for installing dental chairs at LTC institutions, and medical insurance benefits [19-21]. Second, in terms of caring for the oral conditions of LTC residents, dental hygienists have the functions of educating, preventing oral diseases, and promoting oral health and hygiene [22]. For example, in countries such as Japan, South Korea, Sweden, the United States, Australia, and Brazil, dental hygienists provide oral care and examinations as well as improve or assist in the oral knowledge and skills development of institutional caregivers [23-26]. However, Taiwan does not have such a system for oral hygienists [27]. Therefore, the task of promoting the oral health of LTC residents is mainly conducted by institution staff. Factors such as the inadequate knowledge and experience of caregivers in oral care [28, 29] and oral care services are not top priorities $[30,31]$, which affects the willingness of staff to provide oral care to LTC residents.

Therefore, educating and training of knowledge and abilities regarding care for oral diseases among professionals is essential and thus helps improve the oral health of residents [32, 33]. However, such training is difficult to implement in LTC institutions that lack oral health education measures and oral care professionals. Therefore, the formulation of a simple and convenient dry mouth indicator is necessary. Such an indicator can assist care professionals in accurately evaluating dry mouth among residents. Chalmers et al.(2005) reported that attention to saliva status is a crucial training component for caregivers to develop their ability to evaluate oral health [34] and is an objective indicators of dry mouth [15].

This study aim of the study was to evaluate five different diagnostic tests for dry mouth assessment. These were evaluating the residents' characteristics, selfperceived ability to chew food, oral health impact profiles, and self-perceived levels of dry mouth, as well as a repetitive saliva swallowing test.

\section{Methods}

\section{Study design and participants}

The study design is cross-sectional. We explained our research to 27 appropriated registered LTC institutions in central Taiwan, fifteen of which are recruited in this study intern recruited their residents as research participants. This study recruited reviewers who received training regarding the purpose of the study and content of the questionnaire as well as techniques to measure saliva, the required interview skills, and necessary precautions. These reviewers conducted face-to-face interviews with LTC residents and collected questionnaire data.

The inclusion criteria were residents who had (1) excluded those who are diagnosed as neurocognitive disorder and were willing to have written informed consent; (2) lived in LTC institutions in central Taiwan for at least 1 month and were aged $\geq 50$ years, and (3) could provide clear responses. A total of 577 eligible residents were identified, 568 of them were willing to participate. Of the 568 copies of the questionnaire distributed, 560 valid responses were received.

The study was presented to the Institutional Review Board of the Cheng Ching General Hospital, and was approved (HP140026). The data were collected from August 2014 to March 2015.

\section{Measurements}

The research instrument was a self-developed questionnaire created on the basis of previous studies and scales regarding dry mouth [7,33,35-37]. The content validity was evaluated by three experts with experience of performing oral care services in LTC institutions (two nurses in LTC institutions and one dentist). The reliability was assessed using the Cronbach's $\alpha$ coefficient or the Kuder-Richardson formula 20.

The information obtained from the questionnaire survey comprised the residents' demographic attributes, such as gender, educational attainment, age, type of LTC institutions lived in, marital status, average length of LTC stay (months), daily water intake $(\mathrm{mL})$, number of diseases experienced in the last 6 months, and state of oral health care, (i.e., frequency of tooth brushing and gargling per day, and whether the residents had received teeth cleaning in the previous 6 months).

Questionnaire responses confirmed that the residents' textures of food intake in the LTC institutions were divided into four categories: (1) a soft foods (for older adults with poor chewing ability but normal swallowing function); (2) a finely chopped foods (solid food is processed through methods such as mincing and grinding to produce food that can be swallowed without chewing); (3) a semi-liquid foods (solid food is processed through methods such as mincing and grinding, after which it is added to porridge, soup, and drink to that can be swallowed with or without a little chewing); and (4) a fully liquid foods (semiliquid food is completely liquidized in a juicer). The Barthel Index was used to verify LTC residents' 10 activities of daily living (ADL); their scores 
ranged from 0 to 100 , with a lower score indicating higher reliance on others' assistance in daily life [38].

The residents' body mass index (BMI) was calculated after their height in centimeter $(\mathrm{cm})$ and weight in kilogram $(\mathrm{kg})$ were measured. The height of bedridden residents or those unable to stand was measured using their knee height $(\mathrm{cm})$ [39]. Weight measurements were performed using a weighing scale borrowed from the LTC institution. The approximate amount of water in milliliter $(\mathrm{mL})$ drunk by the residents per day was measured using a $350 \mathrm{~mL}$ cup (excluding the amount of water in meals).

\section{Taiwanese short-form of the Oral health impact profile (OHIP-7T) [40]}

The Oral Health Impact Profile (OHIP-7 T) was used to measure the residents' oral health status by asking residents about the problems they had experienced in the past year regarding their mouths, teeth, or dentures. Specifically, this instrument comprised the following seven questions: "have you ever experienced problems related to your teeth or dentures?"; "have you ever been interrupted in meal because of problems related to your teeth or dentures?"; "have you ever experienced discomfort because of problems related to your teeth or dentures?"; "have you ever had difficulties of concentrating because of problems related to your teeth or dentures?"; "have you ever experienced difficulties in pronunciation because of problems related to your teeth or dentures?"; "have you ever encountered difficulties in daily life because of problems related to your teeth or dentures?" and "have your sense of taste deteriorated because of problems related to your teeth or dentures?". The residents replied these questions on a 4-point Likert scale $(0=$ never and $4=$ often $)$. The total possible score was 28 points. A lower score indicate more favorable oral health status. The Cronbach's $\alpha$ of this study was 0.95 .

\section{Self-perceived ability to chew food [41]}

A scale for self-perceived ability to chew food was used to assess the residents' self-evaluated chewing ability. This scale incorporated 24 items: eight fruits were used to test the self-perceived ability of chewing foods with hardness; four fresh foods and meats were used to test the self-perceived ability of chewing foods with toughness; eight cooked vegetables were used to test the selfperceived ability of chewing foods with fracturability; and four viscous foods were used to test the selfperceived ability of chewing foods with viscosity. Table 2 presents the detailed food names. The foods in each category were ranked according to their difficulty to chew [41]. Those listed at the top were the most difficult to chew, and those at the bottom were the easiest to chew. The residents were asked about the difficulty of chewing each category of food, and 1 points were assigned if their response was "easy to chew," whereas 0 points were assigned if their response was "difficult or unable to chew." The highest score for each category is 8 points, yielding a total score of 32 points (total scores of fresh foods, meats, and viscous foods multiplied by 2). A higher score suggested more satisfactory chewing ability. The value of the Kuder-Richardson formula 20 was 0.946, indicating moderate reliability.

\section{Self-perceived levels of dry mouth}

Another scale was conceived to measure residents' selfperceived levels of dry mouth. A total of nine items were designed, which were evaluated using a 5-point Likert scale $(1=$ never and $5=$ frequently). The total score is 45 points; a higher score indicated higher levels of selfperceived dry mouth. This scale examine residents selfperceived symptoms of dry mouth in the last month with the following statements: "I feel dryness in my mouth"; "I feel dryness in my lips"; "I feel that my gums are swollen, hurt, or have a burning sensation"; "I need fluids (e.g., soup or water) to help me swallow my food"; "I need to get up at night to drink water"; "I often feel like my mouth is dry after having a meal;" "I have difficulty eating food without water content"; "I feel dryness in my nose"; and "I feel dryness in my eyes." The Cronbach's $\alpha$ was 0.80 .

\section{Oral moisture checking}

Researches have indicated that decreased oral moisture levels correlate with increased oral dryness [42-44]. Therefore, we measured the actual moisture levels in the mouth of the residents to determine their levels of dry mouth. An oral moisture checking device (Moisture ${ }^{\circ}$, approval number: 22200BZX00640000, Life Co., Ltd., Saitama, Japan) [45] was used for the measurement. As shown in Fig. 1, the sensor on the left was used to detect the moisture of the oral cavity and the green button was for the measurement; the right side of the figure shows the data displayed after the measurement. Because this device is easy and quick in measurement, it is suitable for use among residents in LTC institutions [43, 46]. Measurement was conducted according to the following steps:

1) The surface of the tongue $10 \mathrm{~mm}$ from the apex linguae was measured. The measurement for each resident was conducted using a new sense cover. For each measurement attempt, approximately 200 $\mathrm{g}$ of pressure was applied using the device, and a value was then provided after $2 \mathrm{~s}$. Three consecutive readings were taken, and the median of these is the final measurement. Figure 2 presents 


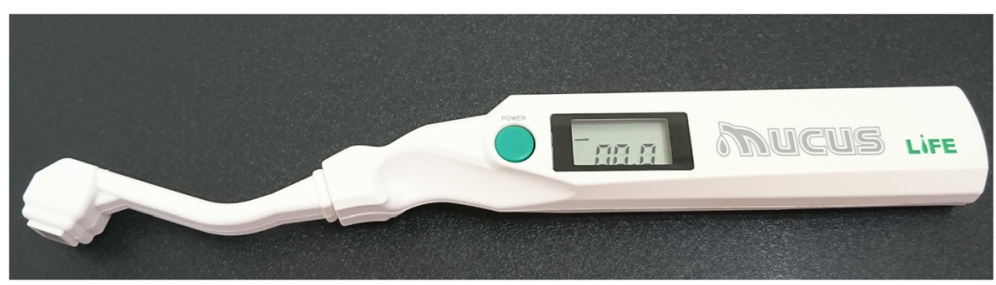

Fig. 1 Oral moisture checking device (Moisture ${ }^{\oplus}$, approval number: 22200BZX00640000, Life Co., Ltd., Saitama, Japan)

the measurement using the oral moisture checking device.

2) The residents were requested to sit and rest for 5 min before the measurement. With reference to the suggestion provided by Saito et al. (2008), the measurement was conducted between two meals, ideally from 10:00 AM to 11:00 AM or from 2:30 PM to 4:30 PM [47].

3) Definitions of the measurement values were as follows: $\geq 29.6$ was defined as normal, $\leq 27.9$ was defined as dry mouth, and 28.0-29.5 was defined as borderline dry mouth [43].

\section{Repetitive saliva swallowing test (RSST)}

The repetitive saliva swallowing test (RSST) was employed to determine the residents' swallowing movements. Oguchi et al. (2000) suggested that RSST is a simple and noninvasive examination [48]. In this test, research personnel assessed the residents' frequency of saliva swallowing by touching their prominentia laryngea through palpation and counting the frequency of swallowing over the span of $30 \mathrm{~s}$. Residents who swallowed saliva three times or more within $30 \mathrm{~s}$ were considered to have normal swallowing ability. Those who swallowed saliva only one or two times were considered to have a moderate risk of dysphagia, and those who could not successfully swallow saliva or choked during the process were considered to have a high risk of dysphagia $[49,50]$.

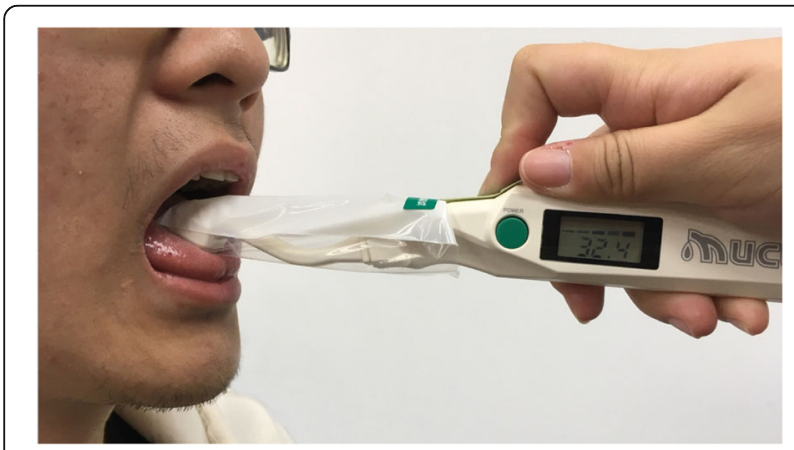

Fig. 2 Measurement of oral moisture degree

\section{Statistical analyses}

Statistical analysis was performed by using SPSS version 19. Descriptive statistics including frequencies, percentages, mean and $95 \%$ confidence interval $(\mathrm{CI})$ were reported. The correlation coefficient was used to confirm the correlation level between the oral moisture measurement and other variables.

Chi-squared automatic interaction detection (CHAID) was employed to create a decision tree. Chi-square automatic interaction detection (CHAID) is a nonmathematical decision tree that apply the stepwise classification method (tree classification method) to detect interactions. A CHAID technique involves a tree analysis between one dependent variable and several independent variables. This method enables classifying both continuous and categorical variables. CHAID operates by examining dependent variables and independent variable through a chi-square test to identify significant variables. If no significant difference exists between the sequential groups of selected independent variables, these variables are combined as one group. That is, each interval of that variable is automatically separated as being mutually independent from other variables through category merging [51].

The dependent variable of this study was oral moisture (interval variable). The independent variable consisted of the residents' demographic characteristics, oral health status, OHIP-7 T results, self-perceived ability to chew food, self-perceived level of dry mouth, and RSST results. We input all independent variables in a CHAID model and did not conduct a hierarchical analysis. To determine the selection sequence of independent variables, this study adopted the automatic model selection method of CHAID. SPSS was used to identify the most significantly lowest probability value in order to divide variables into groups. Likelihood ratio was used in the chi-squared tests. To prevent overfitting, the minimum parent node size was set at 100 and the minimum child node size was set as 50 . The eligibility level and merge level were set to a $p$-value threshold of .05 [51, 52].

\section{Result}

Table 1 presents the residents demographic information. Of all 560 sampled residents, the majority (64.6\%) lived 
Table 1 The Characteristics of the residents

\begin{tabular}{|c|c|c|}
\hline Variable & Number of residents (Percentage) & $\begin{array}{l}\text { Correlation coefficient between oral } \\
\text { moisture and each variable }\end{array}$ \\
\hline \multicolumn{3}{|l|}{ Gender } \\
\hline Male & $250(44.6)$ & -0.03 \\
\hline Female & $310(55.4)$ & \\
\hline \multicolumn{3}{|l|}{ Education } \\
\hline Illiterate & $223(39.8)$ & -0.07 \\
\hline Elementary school & $220(39.3)$ & \\
\hline Junior high school & $58(10.4)$ & \\
\hline High school & $43(7.7)$ & \\
\hline College degree & $16(2.9)$ & \\
\hline \multicolumn{3}{|l|}{ Type of LTC institutions } \\
\hline LTC institutions & $15(2.7)$ & -0.02 \\
\hline Residential Care Home & $362(64.6)$ & \\
\hline Nursing home & $183(32.7)$ & \\
\hline \multicolumn{3}{|l|}{ Marital status } \\
\hline No spouse & $71(12.7)$ & 0.03 \\
\hline Marital status & $131(23.4)$ & \\
\hline Divorced & $51(9.1)$ & \\
\hline Widowed / separated & $307(54.8)$ & \\
\hline \multicolumn{3}{|l|}{ Texture of food intake } \\
\hline Soft foods ${ }^{\mathrm{a}}$ & $297(53.0)$ & \\
\hline Finely chopped foods ${ }^{\mathrm{b}}$ & $133(23.8)$ & $-0.09^{*}$ \\
\hline Semi-liquid diets ${ }^{c}$ & $96(17.1)$ & \\
\hline Full liquid diets ${ }^{d}$ & $34(6.1)$ & \\
\hline Variable & Means $(95 \% \mathrm{Cl})$ & $\begin{array}{l}\text { Correlation coefficient between oral } \\
\text { moisture and each variable }\end{array}$ \\
\hline Average length of LTC stay (months) & $45.78(42.57-48.99)$ & 0.02 \\
\hline Number of diseases experienced & $2.08(1.96-2.20)$ & 0.06 \\
\hline Height (cm) & $157.57(156.80-158.34)$ & 0.02 \\
\hline Body weight (kg) & $56.95(56.05-57.84)$ & 0.06 \\
\hline Body Mass Index (BMI) & $22.91(22.60-23.24)$ & 0.06 \\
\hline Daily water intake $(\mathrm{mL})$ & $899.15(851.15-947.17)$ & 0.03 \\
\hline Activities of daily living scale (ADL) & $67.71(65.28-70.14)$ & $0.14^{* *}$ \\
\hline
\end{tabular}

Note: ${ }^{\text {a }}$ soft foods: for older adults with poor chewing ability but normal swallowing function. ${ }^{b}$ finely chopped foods: solid food is processed through methods such as mincing and grinding to produce food that can be swallowed without chewing. ${ }^{c}$ semi-liquid foods:solid food is processed through methods such as mincing and grinding, after which it is added to porridge, soup, and drink to that can be swallowed with or without a little chewing. ${ }^{\mathrm{d}}$ fully liquid foods: semiliquid food is completely liquidized in a juicer. $\mathrm{cm}$ : centimeter. $\mathrm{kg}$ kilograms, $B M I$ Body mass index, $\mathrm{mL}$ milliliter, $A D L$ Activities of daily living, $C l$ confidence interval. * significant at $p<0.05 ;{ }^{* *}$ significant at $p<0.01 . N=560$

in nursing homes. Their mean ADL score was 67.71 (95\% CI, 65.28-70.14), indicating that most of these residents had mild disabilities. Female residents constituted the majority (55.4\%). The residents had an average age of 77.1 years (95\% CI, 76.14 year - 77.94 years), low educational attainment (79.6\%) were illiterate or had only received an elementary school education), and were experiencing multiple diseases $($ mean $=2.08 ; 95 \%$ CI: 1.96-2.20). Their average length of stay in LTC was approximately 4 years (mean $=45.7$ months; $95 \%$ CI: 42.57 months - 48.99 months). The residents' body mass index were within the normal range $($ mean $=22.91 ; 95 \% \mathrm{CI}: 22.60-23.24)$. The residents' average ADL score was 67.71 (95\% CI, 65.2870.14), indicating they required minor help performing ADLs. The texture of food intake at the institution was mainly soft (53.0\%). Furthermore, their self-estimated quantity of daily water intake was approximately 899.15 $\mathrm{mL}$ on average (95\% CI, $851.15 \mathrm{~mL}-947.17 \mathrm{~mL}$ ). 
All residents performed oral health care at least once per day in the form of brushing their teeth or gargling. However, 90\% residents have not received dental examination within the past half year, suggesting that few of them visited dental clinics to examine their oral health status. In addition, The Self-perceived ability to chew food 的mean total score was 20.22 (95\% CI, 19.4520.98), indicating a moderate-high level of chewing ability (Table 2). The four categories of food each had a score of 8 points, and the residents' self-perceived chewing ability had a score exceeding 4 points, indicating that they still possessed satisfactory chewing ability. The mean score of chewing foods with fracturability (cooked vegetables) was the most satisfactory $(5.87,95 \% \mathrm{CI}$, 5.66-6.07), whereas the mean score of chewing foods with toughness (fresh foods and meats) was the least satisfactory (4.40, 95\% CI, 4.17-4.60).

The average score of the residents' OHIP-7 $\mathrm{T}$ was 3.76 (95\% CI, 3.25-4.28), indicating that they possessed satisfactory oral health-related quality of life (Table 3). Moreover, the mean score for self-perceived level of dry mouth was 16.02 (95\% CI, 15.57-16.50), indicating that on average they perceived dryness in their mouth (Table 4). The mean of oral moisture measurement was 27.97 (95\% CI, 27.63-28.31), which also suggested mouth dryness. The mean frequency of saliva swallowing measured by RSST was 2.97 , which was on the borderline between normal and dry mouth; indicating that overall, the residents may tend to experience some degree of dry mouth (Table 4).

As shown in Tables 1, 2, 3 and 4, the relationships between oral moisture measurement and other variables were verified using the correlation coefficient. A total of five variables achieved significance, namely ADL $(r=0.14, p<0.01)$, frequency of tooth brushing a day $(r=0.11, p<0.05)$, frequency of gargling a day $(r=0.12, p<0.01)$ and RSST $(r=$ $0.17, p<0.01)$; these were all positively correlated with oral moisture measurement. The texture of food intake $(r=-$ $0.09, p<0.05)$ were negatively correlated with oral moisture measurement. The correlation coefficient indicated a low level of correlation between oral measurement and other variables.

Figure 3 shows the results of the CHAID decision tree analysis. Oral moisture measurement was the dependent variable and RSST results, tooth brushing behavior, and age were independent variables. The maximum tree depth was 3 . The analysis revealed that RSST results was the most important variable (adjusted $p<0.000 ; \mathrm{F}=$ 12.793). RSST had three levels of risk: 1) A high risk of dry mouth suggested that the average value of oral moisture was SD: 26.39 and represented dry mouth level. The number of times saliva was swallowed was $\leq 1$ (node 1): this indicated symptoms similar to that of dysphagia; 2) An average of oral moisture value of 27.96 indicated a moderate risk of dry mouth. The number of times saliva was swallowed was 1 to 3 (node 2); 3) An average oral moisture value of 28.827 suggested a low risk of dry mouth. This represented borderline dry mouth, and the number of times saliva was swallowed was over 3 (node3).

The number of times residents brushed their teeth was the next predictive variable for residents with a moderate risk of dry mouth (Adj. $p<0.000, \mathrm{~F}=7.568$ ). Residents with a moderate risk of dry mouth who brushed their teeth more than once had an average oral moisture value of 28.59 (node5); this was higher than the average value of 27.20 (node 4) for residents who brushed their teeth once or less. This demonstrated that the number times residents brushed their teeth affected their oral moisture values if they had a moderate risk of experiencing dry mouth. For residents with a low risk of dry mouth, age is the next crucial predictive variable (adjusted $p<0.024, \mathrm{~F}=9.295$ ). The risk of experiencing borderline dry mouth in residents who were older than 68 years (the average oral moisture value was 28.564; node 7) was higher than that for residents who were aged 68 years or younger (the average oral moisture value was 29.481; node 6).

\section{Discussion}

The researchers excluded residents who were confirmed to have neurocognitive disorders by physicians because of physical and psychological diseases, and explored the factors influencing the measurement of residents' oral moisture levels. CHAID analysis revealed that the RSST result, tooth brushing frequency, and age were three best predictors for oral moisture levels. These finding can assist frontline care professionals in performing quick assessments of oral moisture levels among residents in LTC institutions.

The first significant predictor variable was RSST which correlated with the oral moisture levels of residents. Persson et al. (2018) used the absorbent method to collect residents' saliva, and discovered that the measured saliva values did not affect the RSST [53], which was inconsistent with the results in the present study. The present authors believe this may be caused by different research methods producing different results. Dry mouth is one of the factors affecting oropharyngeal dysphagia [54]. Because dry mouth is a subjective feeling, people with sufficient and insufficient saliva secretion may report symptoms of dry mouth [55] and dysphagia [16]. The results of this study were similar to those of relevant studies in that higher oral moisture levels indicated more satisfactory swallowing function $[16,56]$.

Shunsuke et al. (2018) reported that a diagnosis of oral dryness was required when the oral moisture value (Mucus, Life Co., Ltd.) was < 27 [57]. This result is similar to that of node 1 in the present study; the average value of 
Table 2 State of oral health care and Self-perceived ability to chew food

\begin{tabular}{|c|c|c|c|}
\hline Variable & Number of residents (Percentage) & Means $(95 \% \mathrm{Cl})$ & $\begin{array}{l}\text { Correlation coefficient between oral } \\
\text { moisture and each variable }\end{array}$ \\
\hline \multicolumn{4}{|l|}{ 1. State of oral health care } \\
\hline \multicolumn{4}{|c|}{ (1) Regular dental examination in the previous 6 months } \\
\hline NO & $511(91.3)$ & - & 0.06 \\
\hline Yes & $49(8.8)$ & - & \\
\hline (2) Frequency of tooth brushing per day & - & $1.65(1.56-1.75)$ & $0.11^{*}$ \\
\hline (3) Frequency of gargling per day & - & $1.32(1.20-1.44)$ & $0.12^{* *}$ \\
\hline 2. Self-perceived ability to chew food & & Means $(95 \% \mathrm{Cl})$ & $\begin{array}{l}\text { Correlation coefficient between oral } \\
\text { moisture and total score }\end{array}$ \\
\hline \multicolumn{4}{|c|}{ Fruits (non-pickled fruits, overripe/soft fruits, or juice) } \\
\hline 1.Sugar cane (not juice) & - & $5.24(5.05-5.43)$ & - \\
\hline 2.Sliced guava & - & & \\
\hline 3.Sliced apple or pear & - & & \\
\hline 4.Sliced orange & - & & \\
\hline 5.Sliced star fruit or bell fruit & - & & \\
\hline 6.Sliced melon or tangerine & - & & \\
\hline 7.Sliced watermelon or pineapple & - & & \\
\hline 8.Papaya or banana & - & & \\
\hline \multicolumn{4}{|l|}{ (2) Fresh foods and meats } \\
\hline 1.Squid & - & $4.40(4.17-4.60)$ & - \\
\hline 2.Soy sauce-braised pork ears & - & & \\
\hline 3.Fried chicken leg or chicken fillet & - & & \\
\hline 4.Fish (steamed) & - & & \\
\hline \multicolumn{4}{|c|}{ (3) Cooked vegetables (mainly scrambled or braised food) } \\
\hline 1.Stir-fried peanut & - & $5.87(5.66-6.07)$ & - \\
\hline 2.Boiled bamboo shoots or broccoli & - & & \\
\hline 3.Sliced cucumber or kidney bean & - & & \\
\hline 4.Water spinach or cabbage & - & & \\
\hline \multicolumn{4}{|c|}{ 5.Pickled lettuce in soy sauce or pickled cucumber in soy sauce } \\
\hline 6.Sliced sweet pepper & - & & \\
\hline 7.Steamed sweet potato or taro & - & & \\
\hline 8.Overcooked tomato & - & & \\
\hline \multicolumn{4}{|l|}{ (4) Sticky foods } \\
\hline Malt syrup nougat & - & $4.73(4.45-5.00)$ & - \\
\hline Mochi & - & & \\
\hline Rice cake & - & & \\
\hline Rice dumpling & - & & \\
\hline Total score & - & $20.22(19.45-20.98)$ & 0.07 \\
\hline
\end{tabular}

Note: $N=560 .{ }^{*}$ significant at $p<0.05 ;{ }^{*}$ significant at $p<0.01$. Cl: confidence interval

the residents' oral moisture was lower than 26.392 and the RSST $\leq 1$, indicating that node 1 residents experienced dry mouth and dysphagia. Therefore, caregivers should contact the oral medical team to conduct diagnosis and treatment of dry mouth among node 1 residents.
In addition, node 2 residents exhibited symptoms of dry mouth (average value of oral moisture $=27.96$ ) and dysphagia (RSST $=1-3$ ). The second significant predictor variable was tooth brushing frequency, which correlated with the oral moisture levels of residents of node 
Table 3 Taiwanese Short-form of the Oral Health Impact Profile

\begin{tabular}{|c|c|c|}
\hline Items & Means $(95 \% \mathrm{Cl})$ & $\begin{array}{l}\text { Correlation coefficient between oral } \\
\text { moisture and total score }\end{array}$ \\
\hline $\begin{array}{l}\text { 1. Have you ever experienced problems related } \\
\text { to your teeth or dentures? }\end{array}$ & $0.78(0.68-0.87)$ & - \\
\hline $\begin{array}{l}\text { 2. Have you ever been interrupted in the middle } \\
\text { of a meal because of problems related to your } \\
\text { teeth or dentures? }\end{array}$ & $0.65(0.56-0.74)$ & \\
\hline $\begin{array}{l}\text { 3. Have you ever experienced discomfort because } \\
\text { of problems related to your teeth or dentures? }\end{array}$ & $0.64(0.55-0.73)$ & \\
\hline $\begin{array}{l}\text { 4. Have you ever had difficulties concentrating } \\
\text { because of problems related to your teeth or } \\
\text { dentures? }\end{array}$ & $0.48(0.40-0.56)$ & \\
\hline $\begin{array}{l}\text { 5. Have you ever experienced difficulties in } \\
\text { pronunciation because of problems related to } \\
\text { your teeth or dentures? }\end{array}$ & $0.45(0.37-0.53)$ & \\
\hline $\begin{array}{l}\text { 6. Have you ever encountered difficulties in } \\
\text { daily life because of problems related to your } \\
\text { teeth or dentures? }\end{array}$ & $0.42(0.34-0.49)$ & \\
\hline $\begin{array}{l}\text { 7. Has your sense of taste deteriorated because } \\
\text { of problems related to your teeth or dentures? }\end{array}$ & $0.35(0.28-0.42)$ & \\
\hline Total score & $3.76(3.25-4.28)$ & -0.04 \\
\hline
\end{tabular}

Note: $N=560$. Cl: confidence interval

2. A brushing frequency of $>1$ yielded an average oral moisture value of 28.591, which indicated borderline dry mouth; by contrast, a brushing frequency of $\leq 1$ yielded an average oral moisture value of 27.203 , which indicated dry mouth.

The authors believed that tooth brushing frequency was the protective factor for node 5 residents in maintaining oral moisture. Kakudate et al. (2014) reported that mechanical stimulation of the salivary glands during tooth brushing can increase the amount of saliva [58]. Studies have suggested that older adults whose brushing frequency was less than twice per day have a high probability of dry mouth [58,59]; furthermore, switching to using an electric toothbrush increased the residents' salivary flow [60], indicating that increased salivary flow helps smooth swallowing [56]. Additionally, the intervention results of oral function training programs indicated that they helped increase salivary flow and RSST [61, 62], suggesting that caregivers should focus more on oral hygiene and oral health promotion programs for node 2 residents.

Node 3 residents had borderline dry mouth (average oral moisture value $=28.827$ ); however, they did not exhibit any symptoms of dysphagia (RSST $>3$ ). The third significant predictor variable was age, which associated

Table 4 Self-perceived levels of dry mouth, Oral moisture checking and Repetitive saliva swallowing test

\begin{tabular}{lll}
\hline Items & Means $(95 \% \mathrm{Cl})$ & $\begin{array}{c}\text { Correlation coefficient between } \\
\text { oral moisture and total score }\end{array}$ \\
\hline 1. Self-perceived levels of dry mouth & $2.09(2.00-2.18)$ & - \\
1.I feel dryness in my mouth & $2.00(1.91-2.08)$ & $1.31(1.25-1.37)$ \\
2.I feel dryness in my lips & $1.92(1.82-2.01)$ & $2.07(1.97-2.17)$ \\
3.I feel that my gums are swollen, hurt, or have a burning sensation & $1.72(1.65-1.80)$ & -0.06 \\
4.I need fluids (e.g., soup or water) to help me swallow my food & $1.93(1.83-2.02)$ & 1 \\
5.I need to get up at night to drink water & $1.36(1.30-1.42)$ & $1.65(1.58-1.73)$ \\
6.I often feel like my mouth is dry after having a meal & $16.02(15.57-16.50)$ & $0.17^{* *}$ \\
7.I have difficulty eating food with no water content & $27.97(27.63-28.31)$ & $2.97(2.84-3.11)$ \\
8.I feel dryness in my nose & &
\end{tabular}

Note: $N=560 .{ }^{*}$ significant at $p<0.01$. Cl: confidence interval 


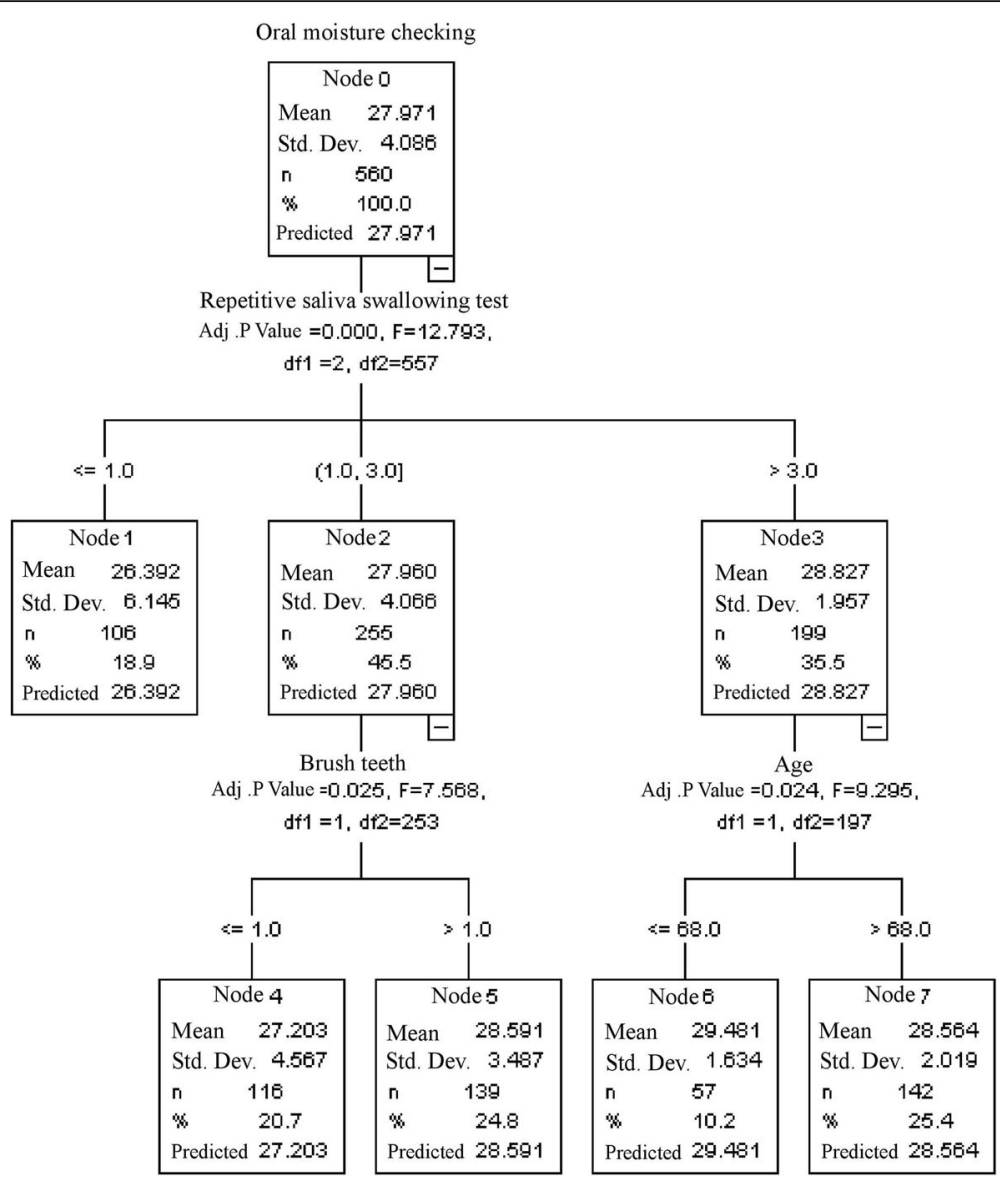

Fig. 3 Decision Tree constructed by CHAID algorithm

with the oral moisture levels of residents of node 3. Dry mouth is closely correlated with aging and salivary gland degeneration $[3,15]$. Previous studies have used varying cut-off points for age. For example, some studies have identified older participants by age of $\geq 65$ years, $[11,63]$ $\geq 75$ years, [64] or $\geq 85$ years $[65,66]$. In the present study, age of 68 years was determined as the cut-off point. The results of this study might have been influenced by limited sample size or methodological differences. We found that the oral moisture level of residents with RSST results $\geq 3$ and age $\leq 68$ years were at approximately normal levels; however, those of residents age > 68 years were borderline. This finding furtherly verified that more attention should be directed to oral health status among residents aged $>68$ years in LTC institutions even if they possess normal swallowing function.

We believe that the results highlight the importance of enhancing care professionals' knowledge in LTC institutions that lack medical personnel specializing in oral health care or facilities for dry mouth assessment. Teaching such professionals about oral moisture checking and RSST methods, which help ensure the tooth brushing frequency and age indicators of residents, can assist caregivers in simply and conveniently providing assessment and oral care $[49,67]$. In addition, collaboration with professional dental and medical teams can provide residents with more satisfactory oral health care.

This study had four research limitations. First, we excluded residents who were verified to have neurocognitive disorder by physicians, and the respondents' average ADL score was 67.71 (95\% CI, 65.28-70.14), indicating the residents' need for minor help in performing ADLs. Therefore, the results cannot be extended to all LTC residents. However, because oral moisture checking instruments enable easy and quick assessment of residents' level of oral dryness, such instruments can be used in the future to evaluate the level of oral dryness of patients who are bedridden, have severe disabilities, or have neurocognitive disorders.

Second, the aim of this study was to conduct a straightforward measurement of saliva moisture to examine factors influencing residents' dry mouth status. Furthermore, the aim was to help institution personnel focus on simple observation indicators and provide oral health care assessments for residents. We did not specifically focus on the effect of different diseases on dry 
mouth because the level of dry mouth caused by systematic diseases (e.g., Sjögren syndrome, diabetes, kidney disease, and thyroid diseases) requires various differential diagnoses to be performed (e.g., serum biochemistry, examination of immunology, radiological examination of salivary glands, pathological examination, and examination of salivary cytokines) [68]. Furthermore, diagnoses and medical treatments must be performed by a professional medical team [69].

Third, most residents knew the functions of the medicine they should take, but were unable to correctly provide its product or scientific name. Therefore, this study did not account for the type and dosage of medications that the residents took. More than 500 types of medication can cause dry mouth, clinically such as antihistamines (e.g., diphenhydramine, and chlorpheniramine), anticholinergic agents (e.g., dicyclomine and oxybutynin), and hypotensive agents (e.g., captopril and methyldopa) [70]. Tan et al. (2018) reported that using medication with antimuscarinic properties for urinary frequency and incontinence and medication usage for the genitourinary and nervous systems in addition to antidepressants and psycholeptics were associated with dry mouth occurrence [71]. Moreover, the use of antihypertensive and cardiovascular drugs increases the risk of dry mouth [72]. A total of $70 \%$ of older adults in care institutions used more than 5 types of medications every day, which showed that the numbers and doses of medications are complex factors in such an analysis [73]. Future research should include doctor and pharmacy teams to evaluate the correlation between medication usage in older adults in care institutions and their dry mouth statuses.

Fourth, the self-developed questionnaires included "The Characteristics of the Residents," "Self-perceived levels of dry mouth," and "Self-perceived ability to chew food." The questionnaire content may have featured a risk of bias and was not subject to verification by different groups. Although we adopted measures such as expert validity and statistical verification to ensure validity and reliability, some potential factors of dry mouthrelated care were not considered. Therefore, the results may be biased and should be treated with caution.

Despite these limitations, this study provided empirical evidence for determining factors that influence levels of dry mouth among residents living in LTC institutions. The results can facilitate assessment of dry mouth among high-risk residents, thereby promoting individualized oral care measures. Our results provide frontline care professionals with a set of simple indices for dry mouth. Although the results indicated that the residents' self-perceived oral statuses (i.e., oral health status, dry mouth status, and chewing ability) do not associated with their oral moisture levels.
Future research should explore other possible methods that could be employed for self-assessed detection of dry mouth. Moreover, the interaction effect between diseases of different levels and oral moisture is a pertinent topic for future studies.

\section{Conclusion}

The research results verified that RSST results, tooth brushing frequency, and age were the three primary factors influencing dry mouth in the residents living in LTC institutions. RSST $<1$ will result in symptoms of dry mouth and dysphagia. For residents who had borderline oral moisture levels and suspected swallowing disorder, dry mouth correlated with tooth brushing frequency. For residents aged $>68$ years, oral moisture levels may be inadequate even with normal RSST results. Management and care professionals in LTC institutions should incorporate these finding into existing oral care services and evaluate the results.

\section{Abbreviations}

ADL: Activities of daily living; BMI: Body mass index; CHAID: Chi-squared automatic interaction detection; $\mathrm{Cl}$ : Confidence interval; $\mathrm{cm}$ : centimeter; kg: kilograms; LTC: Long-term care; mL: milliliter; OHIP-7 T: Taiwanese shortform of the Oral Health Impact Profile; RSST: Repetitive saliva swallowing test

\section{Acknowledgements}

Not applicable.

\section{Authors' contributions}

YMC and YPH designed the research and coordinated data collection. SHL, SJL and SWH analyzed the data gave advice on the data analysis. YMC and YPH participated in drafting and editing. All authors read and approved the final manuscript.

\section{Funding}

This study was kindly supported by grants from the Chung Kang Branch, Cheng Ching Hospital $(103075 \mathrm{H})$. The funding body did not contribute to the design of the study, collection, analysis and interpretation of the data or writing of the manuscript.

\section{Availability of data and materials}

The datasets analyzed in this study are not publicly available because of older people confidentiality issues but are available from the corresponding author on reasonable request.

\section{Ethics approval and consent to participate}

This study was approved by the Institutional Review Board of Cheng Ching General Hospital (HP140026).

\section{Consent for publication}

Not applicable.

\section{Competing interests}

The authors declare that they have no competing interests.

\section{Author details}

${ }^{1}$ Department of Healthcare Administration, Asia University, Taichung City, Taiwan. ${ }^{2}$ School of Pharmaceutical Sciences and Medical Technology, Putian University, Putian City, China. ${ }^{3}$ Department of Long-term Care, National Quemoy University, No. 1 University Rd., Jinning Township, Kinmen County 89250, Taiwan. ${ }^{4}$ Department of Medical Research, China Medical University Hospital, China Medical University, Taichung, Taiwan. 
Received: 11 September 2018 Accepted: 24 May 2019

Published online: 13 June 2019

\section{References}

1. Andersson P, Renvert S, Sjogren P, Zimmerman M. Dental status in nursing home residents with domiciliary dental care in Sweden. Community Dent Health. 2017;34(4):203-7.

2. Cho EP, Hwang SJ, Clovis JB, Lee TY, Paik DI, Hwang YS. Enhancing the quality of life in elderly women through a programme to improve the condition of salivary hypofunction. Gerodontology. 2012;29(2):e972-80

3. Liu B, Dion MR, Jurasic MM, Gibson G, Jones JA. Xerostomia and salivary hypofunction in vulnerable elders: prevalence and etiology. Oral Surg Oral Med Oral Pathol Oral Radiol. 2012:114(1):52-60.

4. Narhi T, Meurman J, Ainamo A, Nevalainen J, Schmidt-Kaunisaho K, Siukosaari P, Valvanne J, Erkinjuntti T, Tilvis R, Makila E. Association between salivary flow rate and the use of systemic medication among 76-, 81-, and 86-year-old inhabitants in Helsinki, Finland. J Dent Res. 1992;71(12):1875-80.

5. Iwasaki M, Yoshihara A, Ito K, Sato M, Minagawa K, Muramatsu K, Watanabe R, Manz MC, Ansai T, Miyazaki H. Hyposalivation and dietary nutrient intake among community-based older Japanese. Geriatr Gerontol Int. 2016:16(4): 500-7.

6. Muñoz-González C, Vandenberghe-Descamps M, Feron G, Canon F, Labouré $H$, Sulmont-Rossé C. Association between salivary hypofunction and food consumption in the elderlies. A systematic literature review. J Nutr Health Aging. 2018;22(3):407-19.

7. Cassolato SF, Turnbull RS. Xerostomia: clinical aspects and treatment Gerodontology. 2003;20(2):64-77.

8. Villa $\mathrm{A}$, Connell $\mathrm{CL}$, Abati S. Diagnosis and management of xerostomia and hyposalivation. Ther Clin Risk Manag. 2015;11:45.

9. Villa A, Polimeni A, Strohmenger L, Cicciu D, Gherlone E, Abati S. Dental patients' self-reports of xerostomia and associated risk factors. J Am Dent Assoc (1939). 2011;142(7):811-6.

10. Marino R, Schofield M, Wright C, Calache H, Minichiello V. Self-reported and clinically determined oral health status predictors for quality of life in dentate older migrant adults. Community Dent Oral Epidemiol. 2008;36(1): 85-94.

11. Porter J, Ntouva A, Read A, Murdoch M, Ola D, Tsakos G. The impact of oral health on the quality of life of nursing home residents. Health Qual Life Outcomes. 2015;13(1):102.

12. Kakudate N, Muramatsu T, Endoh M, Satomura K, Koseki T, Sato Y, Ito K, Ogasawara T, Nakamura S, Kishimoto E. Factors associated with dry mouth in dependent J apanese elderly. Gerodontology. 2014;31(1):11-8.

13. Ichikawa K, Sakuma S, Yoshihara A, Miyazaki H, Funayama S, Ito K, Igarashi A Relationships between the amount of saliva and medications in elderly individuals. Gerodontology. 2011;28(2):116-20

14. Ogasawara T, Andou N, Kawase S, Kawase Y, Matsuo K, Ozaki Y, Kakinoki Y Potential factors responsible for dryness of the dorsum of the tongue in elderly requiring care. Gerodontology. 2008;25(4):217-21.

15. Thomson WM. Dry mouth and older people. Aust Dent J. 2015;60:54-63.

16. Brochier CW, Hugo FN, Rech RS, Baumgarten A, Hilgert JB. Influence of dental factors on oropharyngeal dysphagia among recipients of long-term care. Gerodontology. 2018;35(4):333-8.

17. Ohara $Y$, Yoshida N, Kono $Y$, Hirano H, Yoshida H, Mataki S, Sugimoto K. Effectiveness of an oral health educational program on community-dwelling older people with xerostomia. Geriatr Gerontol Int. 2015;15(4):481-9.

18. Chen S-C, Hu Y-J, Zhagn R-S, Yen M-F, Zhang J-S. Effect of oral health education for the elderly in the community and long-term care institutions. Taiwan J Public Health. 2018;37(3):295-308.

19. Bots-VantSpijker PC, Vanobbergen JN, Schols JM, Schaub RM, Bots CP, de Baat C. Barriers of delivering oral health care to older people experienced by dentists: a systematic literature review. Community Dent Oral Epidemiol. 2014;42(2):113-21.

20. Hsieh Y-P, Lan S-J, Huang Y-C, Chu C-L, Chen Y-H, Wu S-H, Liu C-Y, Hung T$P$, Peng $C-Y$, Chen $Y-C$. Factors affecting caregivers' perceptions of residents' oral health in long-term care facilities in Taiwan. Geriatr Nurs. 2012;33(5):350-7.

21. Ching-Fen L. Dental visit behavior and satisfaction of dental service for elderly residents in long-term care institutions in Kaohsiung area. Kaohsiung: Kaohsiung Medical University; 2010.

22. Monajem S. Integration of oral health into primary health care: the role of dental hygienists and the WHO stewardship. Int J Dent Hyg. 2006:4(1): 47-51.
23. Hopcraft M, Morgan M, Satur J, Wright F. Utilizing dental hygienists to undertake dental examination and referral in residential aged care facilities. Community Dent Oral Epidemiol. 2011;39(4):378-84.

24. Nederfors T, Paulsson G, Isaksson R, Fridlund B. Ability to estimate oral health status and treatment need in elderly receiving home nursing--a comparison between a dental hygienist and a dentist. Swed Dent J. 2000; 24(3):105-16.

25. Lee M-J, Kim D-K, Hwang S-J, Oh S-H. Elderly welfare system and role of dental hygienists in Korea and Japan. J Dental Hygiene Sci. 2018;18(3): 172-81.

26. Sanglard-Oliveira CA, Werneck MAF, Lucas SD, Abreu MHNG. Exploring professionalization among Brazilian oral health technicians. Hum Resour Health. 2012:10(1):5.

27. Cheng YA, Huang ST, Hsieh ST. A predictive study on the role and function of the dental hygienist in Taiwan. Int J Dent Hyg. 2007;5(2):103-8.

28. Wårdh I, Andersson L, Sörensen S. Staff attitudes to oral health care. A comparative study of registered nurses, nursing assistants and home care aides. Gerodontology. 1997;14(1):28-32.

29. Visschere L, Baat C, Meyer L, Putten GJ, Peeters B, Söderfelt B, Vanobbergen $J$. The integration of oral health care into day-to-day care in nursing homes: a qualitative study. Gerodontology. 2015;32(2):115-22.

30. Coleman P, Watson NM. Oral care provided by certified nursing assistants in nursing homes. J Am Geriatr Soc. 2006:54(1):138-43.

31. Ek K, Browall M, Eriksson M, Eriksson I. Healthcare providers' experiences of assessing and performing oral care in older adults. Int J Older People Nursing. 2018:e12189.

32. Wang T-F, Huang C-M, Chou C, Yu S. Effect of oral health education programs for caregivers on oral hygiene of the elderly: a systemic review and meta-analysis. Int J Nurs Stud. 2015;52(6):1090-6.

33. Nicol R, Petrina Sweeney M, McHugh S, Bagg J. Effectiveness of health care worker training on the oral health of elderly residents of nursing homes. Community Dent Oral Epidemiol. 2005:33(2):115-24.

34. Chalmers J, King P, Spencer A, Wright F, Carter K. The oral health assessment tool—validity and reliability. Aust Dent J. 2005:50(3):191-9.

35. Donaldson M, Epstein J, Villines D. Managing the care of patients with Sjögren syndrome and dry mouth. J Am Dent Assoc. 2014;145(12):1240-7.

36. Villa A, Abati S. Risk factors and symptoms associated with xerostomia: a cross-sectional study. Aust Dent J. 2011:56(3):290-5.

37. Locker D. Dental status, xerostomia and the oral health-related quality of life of an elderly institutionalized population. Spec Care Dentist. 2003:23(3):86-93.

38. Mahoney FI, Barthel DW: Functional evaluation: the Barthel index: a simple index of independence useful in scoring improvement in the rehabilitation of the chronically ill. Maryland state medical journal 1965.

39. Cheng $H$, See $L$, Shieh $Y$. Estimating stature from knee height for adults in Taiwan. Chang Gung Med J. 2001;24(9):547-56.

40. Kuo H-C, Chen J-H, Lai S-K, Shen Y-C, Wang J-C, Yang Y-H. Development and validation of the Taiwanese short-form of the Oral health impact profile (OHIP-7T). Taiwan J Public Health. 2013;32(4):393-402.

41. Hsu KJ, Lee HE, Wu YM, Lan SJ, Huang ST, Yen YY. Masticatory factors as predictors of oral health-related quality of life among elderly people in Kaohsiung City, Taiwan Qual Life Res. 2014·23(4):1395-405.

42. Osailan S, Pramanik R, Shirlaw P, Proctor G, Challacombe S. Clinical assessment of oral dryness: development of a scoring system related to salivary flow and mucosal wetness. Oral Surg Oral Med Oral Pathol Oral Radiol. 2012;114(5):597-603.

43. Fukushima Y, Yoda T, Araki R, Sakai T, Toya S, Ito K, Funayama S, Enoki Y, Sato T. Evaluation of oral wetness using an improved moisture-checking device for the diagnosis of dry mouth. Oral Sci Int. 2017;14(2):33-6.

44. Kleinberg I, Wolff M, Codipilly D. Role of saliva in oral dryness, oral feel and oral malodour. Int Dent J. 2002;52(S5P1):236-40.

45. Measurement of oral moisture degree [http://www.life-qol.net/index.php]

46. Fukushima Y, Yoda T, Kokabu S, Araki R, Murata T, Kitagawa Y, Omura K, Toya S, Ito K, Funayama S. Evaluation of an oral moisture-checking device for screening dry mouth. Open J Stomatology. 2013;3(08):440.

47. Mika S, Yukiko O, Nobutaka K, Masatsune Y, Chikara S. A study of moisture content in the Oral mucosa in the elderly : part II. Investigation moisture content in the Oral mucosa in the elderly population residing at a nursing home. Jpn J Gerodontol. 2008:23(2):97-105.

48. Oguchi K, Saitoh E, Mizuno M, Baba M, Okui M, Suzuki M. The repetitive saliva swallowing test (RSST) as a screening test of functional dysphagia. Jpn J Rehabil Med. 2000;37(6):375-82. 
49. Oguch K, Saitoh E, Mizuno M, Baba M, Okui M, Suzuki M. The repetitive saliva swallowing test (RSST) as a screening test of functional dysphagia (2) validity of RSST. Jpn J Rehabil Med. 2000;37(6):383-8.

50. Oguchi K, Satioh E, Mizuno M, Baba M, Okui M, Suzuki M. The repetitive saliva swallowing test (RSST) as a screening test of functional dysphagia (1) Normal values of RSST. Jpn Assoc Rehabil Mid. 2000;37:375-82.

51. Song Y-Y, Lu Y. Decision tree methods: applications for classification and prediction. Shanghai Arch Psychiatry. 2015;27(2):130-5.

52. Baizyldayeva U, Uskenbayeva R, Amanzholova S. Decision making procedure: applications of IBM SPSS cluster analysis and decision tree. World Appl Sci J. 2013;21(8):1207-12.

53. Persson E, Wårdh I, Östberg P. Repetitive saliva swallowing test: norms, clinical relevance and the impact of saliva secretion. Dysphagia. 2018:1-8.

54. Reddy SS, Priyadharshini R. Oropharyngeal dysphagia: understanding the etiology. J Otolaryngol Res. 2017;1:115.

55. Ohara Y, Hirano H, Yoshida H, Obuchi S, Ihara K, Fujiwara Y, Mataki S. Prevalence and factors associated with xerostomia and hyposalivation among community-dwelling older people in J apan. Gerodontology. 2016; 33(1):20-7.

56. Furuta M, Yamashita Y. Oral health and swallowing problems. Curr Phys Med Rehabil Rep. 2013;1(4):216-22.

57. Minakuchi S, Tsuga K, Ikebe K, Ueda T, Tamura F, Nagao K, Furuya J, Matsuo K, Yamamoto K, Kanazawa M. Oral hypofunction in the older population: position paper of the Japanese Society of Gerodontology in 2016. Gerodontology. 2018.

58. Kakudate N, Muramatsu T, Endoh M, Satomura K, Koseki T, Sato Y, Ito K, Ogasawara T, Nakamura S, Kishimoto E, et al. Factors associated with dry mouth in dependent Japanese elderly. Gerodontology. 2014;31(1):11-8.

59. Islas-Granillo H, Borges-Yáñez A, Fernández-Barrera MÁ, Ávila-Burgos L, Patiño-Marín N, de Lourdes Márquez-Corona M, Mendoza-Rodríguez M, Medina-Solís CE, de Lourdes Márquez-Corona M, Mendoza-Rodríguez M, Medina-Solís CE. Relationship of hyposalivation and xerostomia in Mexican elderly with socioeconomic, sociodemographic and dental factorssociodemographic and dental factors. Sci Rep. 2017;7:40686.

60. Papas A, Singh M, Harrington D, Rodriguez S, Ortblad K, De Jager M, Nunn M. Stimulation of salivary flow with a powered toothbrush in a xerostomic population. Spec Care Dentist. 2006;26(6):241-6.

61. Ibayashi H, Fujino Y, Pham T-M, Matsuda S. Intervention study of exercise program for oral function in healthy elderly people. Tohoku J Exp Med. 2008:215(3):237-45.

62. Nam M, Uhm D. A comparative study of the effects of intra and extra circumoral exercise for older people on oral health at nursing homes: a non-equivalent trial. J Adv Nurs. 2016;72(9):2114-23.

63. Johansson AK, Johansson A, Unell L, Ekback G, Ordell S, Carlsson GE. A 15-yr longitudinal study of xerostomia in a Swedish population of 50-yr-old subjects. Eur J Oral Sci. 2009;117(1):13-9.

64. Benn A, Broadbent J, Thomson W. Occurrence and impact of xerostomia among dentate adult new Zealanders: findings from a national survey. Aust Dent J. 2015;60(3):362-7.

65. Morino T, Ookawa K, Haruta N, Hagiwara Y, Seki M. Effects of professional oral health care on elderly: randomized trial. Int J Dent Hyg. 2014;12(4): 291-7.

66. Desoutter A, Soudain-Pineau M, Munsch F, Mauprivez C, Dufour T, Coeuriot $J$ L. Xerostomia and medication: a cross-sectional study in long-term geriatric wards. J Nutr Health Aging. 2012;16(6):575-9.

67. Inui A, Takahashi I, Kurauchi S, Soma Y, Oyama T, Tamura Y, Noguchi T, Murashita K, Nakaji S, Kobayashi W. Oral conditions and dysphagia in Japanese, community-dwelling middle- and older- aged adults, independent in daily living. Clin Interv Aging. 2017;12:515-21.

68. Ohyama K, Moriyama M, Hayashida JN, Tanaka A, Maehara T, leda S, Furukawa S, Ohta M, Imabayashi Y, Nakamura S. Saliva as a potential tool for diagnosis of dry mouth including Sjögren's syndrome. Oral Dis. 2015;21(2): 224-31

69. Porter S, Scully C, Hegarty A. An update of the etiology and management of xerostomia. Oral Surg Oral Med Oral Pathol Oral Radiol Endod. 2004;97(1): 28-46.

70. Guggenheimer J, Moore PA. Xerostomia: etiology, recognition and treatment. J Am Dent Assoc. 2003;134(1):61-9.

71. Tan EC, Lexomboon D, Sandborgh-Englund G, Haasum Y, Johnell K. Medications that cause dry mouth as an adverse effect in older people: a systematic review and metaanalysis. J Am Geriatr Soc. 2018;66(1):76-84.
72. Hayashida J-N, Minami S, Moriyama M, Toyoshima T, Shinozaki S, Tanaka A, Maehara T, Nakamura S. Differences of stimulated and unstimulated salivary flow rates in patients with dry mouth. J Oral Maxillofacial Surg Med Pathol. 2015;27(1):96-101.

73. Advinha AM, de Oliveira-Martins S, Mateus V, Pajote SG, Lopes MJ. Medication regimen complexity in institutionalized elderly people in an aging society. Int J Clin Pharm. 2014;36(4):750-6.

\section{Publisher's Note}

Springer Nature remains neutral with regard to jurisdictional claims in published maps and institutional affiliations.
Ready to submit your research? Choose BMC and benefit from:

- fast, convenient online submission

- thorough peer review by experienced researchers in your field

- rapid publication on acceptance

- support for research data, including large and complex data types

- gold Open Access which fosters wider collaboration and increased citations

- maximum visibility for your research: over $100 \mathrm{M}$ website views per year

At BMC, research is always in progress.

Learn more biomedcentral.com/submissions 